\title{
STUDIES IN BLOOD COAGULATION : THE COAGULATION PROPERTIES OF CERTAIN GLOBULIN FRACTIONS OF NORMAL HUMAN PLASMA IN VITRO ${ }^{1,2}$
}

\author{
By F. H. L. TAYLOR, C. S. DAVIDSON, H. J. TAGNON, M. A. ADAMS, \\ A. H. MACDONALD, AND GEORGE R. MINOT \\ (From the Thorndike Memorial Laboratory, Second and Fourth Medical Services (Harvard), \\ Boston City Hospital, and the Department of Medicine, Harvard Medical School, Boston)
}

(Received for publication March 3, 1945)

Previous studies from this laboratory have demonstrated that, at least, 2 protein fractions can be prepared from cell and calcium-free human plasma which have a definite effect of lowering the coagulation time of hemophilic blood (1 to 4). One of these protein fractions requires the presence of both calcium ion and prothrombin in order to exhibit its activity. The other acts as a true thrombin since it can convert fibrinogen to fibrin in the absence of calcium and prothrombin.

It has been further demonstrated that the former protein preparation, presumably associated with the euglobulin fraction, can by treatment with chloroform be converted into a protein preparation having proteolytic activity $(5,6)$. The physiologic rôle of this enzyme has not been determined. However, it is known that it can convert prothrombin to thrombin and hence in appropriate amounts induce blood coagulation (7). In larger amounts it can digest fibrinogen before fibrin formation can take place.

Various preparations of globulin fractions from pooled normal human plasma were placed at our disposal for study of their coagulation properties. ${ }^{3}$ A summary of our results has been presented by other workers (8).

The present communication concerns the activity of these globulin fractions in vitro. In the

\footnotetext{
1 This paper is No. 38 in the "Studies of Plasma Proteins" of the Harvard Medical School, Boston, Massachusetts, on products developed by the Department of Physical Chemistry from blood collected by the American Red Cross.

2 The expenses of this investigation were defrayed in part by gifts from the Smith, Kline and French Laboratories, Philadelphia, and in part by a grant "In recognition of Dr. Francis W. Peabody's services to the Foundation" by the Ella Sachs Plotz Foundation.

${ }^{8}$ Through the courtesy of Professor E. J. Cohn and Dr. J. T. Edsall.
}

accompanying paper a brief preliminary note on the in vivo action of one of them is presented.

\section{GENERAL METHODS}

All fractions of globulins and parent plasmas were received as dry powder and were put into 4 per cent solution in either isotonic salt solution or in 0.25 per cent sodium citrate in 0.85 per cent sodium chloride solution. The $\mathrm{pH}$ of the solutions was adjusted to 7.0 to 7.5 using a glass electrode. The total nitrogen of the final centrifuged solution was determined by a micro Kjeldahl method. The nomenclature used in the description of the fractions was that developed by Cohn and his coworkers (9). Over 140 globulin fractions have been studied. Most of these studies were made during the period of standardization of methods of preparation and will not be reported because the final fractions were not comparable. The fractions presented in this communication are those obtained after the methods of preparation had been satisfactorily standardized so that duplication of results from fraction to fraction was possible.

The average composition of the various fractions mentioned in this paper are stated in $\mathrm{Ta}$ ble I. ${ }^{4}$

\section{DEFINITIONS AND METHODS}

Fibrinogen is that fraction of the plasma protein which coagulates on the addition of thrombin alone. It was tested for by the addition of $0.1 \mathrm{ml}$. of a 12.5 per cent solution of a highly potent thrombin solution ${ }^{5}$ to $1 \mathrm{ml}$. of a 4 per cent solution of the fraction. The time of coagulation, if such occurred, was used as an index of the presence of and a rough quantitative approximation of the amount of fibrinogen.

Prothrombin is the precoursor of thrombin. It rapidly develops thrombic activity on the addition of thromboplastin and calcium ions. A similar conversion can be made by the action of certain

4 These are as given by Cohn, Oncley, Strong, Hughes, and Armstrong (9).

5 Lederle "Hemostatic Globulin" (4). 
TABLE I

Composition of fractions

\begin{tabular}{|c|c|c|c|c|c|}
\hline Fraction & Albumin & $\alpha \underset{\text { lin }}{\text { Globu- }}$ & $\beta \underset{\text { lin }}{\beta}$ & $\gamma$ Globu- & $\begin{array}{l}\text { Fibrino- } \\
\text { gen }\end{array}$ \\
\hline $\begin{array}{c}\mathrm{V}^{*} \\
\text { IV } \\
\text { III-2 } \\
\text { III-1 } \\
\text { II } \\
\text { I }\end{array}$ & $\begin{array}{c}\text { per cent } \\
98.5 \\
15 \\
0 \\
0 \\
1 \\
5\end{array}$ & $\begin{array}{c}\text { per cent } \\
1.5 \\
55 \\
10 \\
4 \\
0 \\
4\end{array}$ & $\begin{array}{c}\text { per cent } \\
0 \\
28 \\
75 \\
35 \\
1 \\
19\end{array}$ & $\begin{array}{c}\text { per cent } \\
0 \\
2 \\
15 \\
61 \\
98 \\
11\end{array}$ & $\begin{array}{c}\text { per cent } \\
0 \\
0 \\
0 \\
0 \\
0 \\
61\end{array}$ \\
\hline
\end{tabular}

* Previous studies have shown this fraction devoid of anti-hemophilic properties.

proteolytic enzymes with and without calcium ions $(10,7)$ and under certain circumstances spontaneously (11). The detection of prothrombin in a fraction of the plasma globulin was made by a modification (12) of Quick's (13) procedure. Instead of the customary $0.1 \mathrm{ml}$. of plasma, 0.1 ml. of a 4 per cent solution of the fraction was used. When the fraction contained no fibrinogen, this material in the purest form obtainable was added in the reaction vessel before the addition of calcium and thromboplastin. Since all preparations were studied in 4 per cent concentration, the "prothrombin time" was a rough index of the amount present.

Thrombin is that activity developed in plasma which can convert fibrinogen to fibrin without the intervention of either calcium ion or thromboplastin. The presence of thrombin in a fraction was tested for by the addition of $0.5 \mathrm{ml}$. of a 4 per cent solution of the fraction to $0.5 \mathrm{ml}$. of a solution of the purest obtainable fibrinogen. The test was always carried out in the presence of an excess of sodium citrate.

Anti-hemophilic activity [plasma thromboplastin of Howell (14)] has been shown to be associated with the plasma euglobulins $(1,3)$. It is capable in the presence of calcium ions of producing thrombin from prothrombin or alternatively of neutralizing a circulating antithrombin. The antihemophilic activity of a fraction was determined by measuring the effect of $0.1 \mathrm{ml}$. of a 4 per cent solution of the fraction at $37.5^{\circ} \mathrm{C}$. and $\mathrm{pH} 7$ to 7.5 on the coagulation time of $2 \mathrm{ml}$. of hemophilic blood. Usually 2 dilutions of the 4 per cent solution of the protein fraction with 0.85 per cent saline solution to $1 / 10$ and $1 / 100$ of the former concentration were made. When fractions were extremely active there was marked reduction of the clotting time of the hemophilic blood even at $1 / 100$ dilution. Sometimes activity was found at $1 / 10$ and $1 / 100$ but none when the undiluted material was used. This was presumably due to excessive amounts of citrate ion present in the protein fraction.

Proteolytic activity after chloroform. Twentyfive ml. of a 4 per cent solution of the preparation was shaken briefly with $1 / 10$ its volume of chloroform as previously described $(7,5)$. When digestion was complete, equal amounts of the chloroform extracts and of 1 per cent casein were mixed and incubated at $\mathrm{pH} 7$ for 96 hours. The increase in non-protein nitrogen was taken as an index of the activity of the proteolytic enzyme content of the plasma. A control consisted of a solution of 1 per cent casein mixed with an equal volume of 0.25 sodium citrate in 0.85 per cent saline. The preparations remained sterile as indicated by bacteriologic examination.

Proteolytic activity without treatment with chloroform. Occasionally certain protein fractions of human plasma have proteolytic activity without previous treatment with chloroform. This activity was tested qualitatively by observing the lytic action of the fraction on a fibrin clot. Quantitatively it was determined by the amount of nonprotein nitrogen produced by the addition of a mixture of equal volumes of a 4 per cent solution of the fraction and a 1 per cent casein solution at $\mathrm{pH} 7.4$ at room temperature for 96 hours.

\section{RESULTS}

\section{(The complete data are presented in Table II)}

Antihemophilic activity. The antihemophilic activity of human plasma was distributed in Fractions I and II + III and was markedly diminished in Fraction IV. From the data of Table II it appears that great activity in reducing the coagulation time of hemophilic blood resides in Fraction I which likewise contains the bulk of the fibrinogen. From a study of runs 119, 123, 124 and 125, it would appear that a marked concentration of the activity over that displayed by the parent plasma was achieved by the method of preparation of Fraction I. However, it is well known (15) that antihemophilic activity rapidly disappears from plasma. Fresh plasma has a 
TABLE II

Coagulation properties of fractions of normal human plasma in vitro

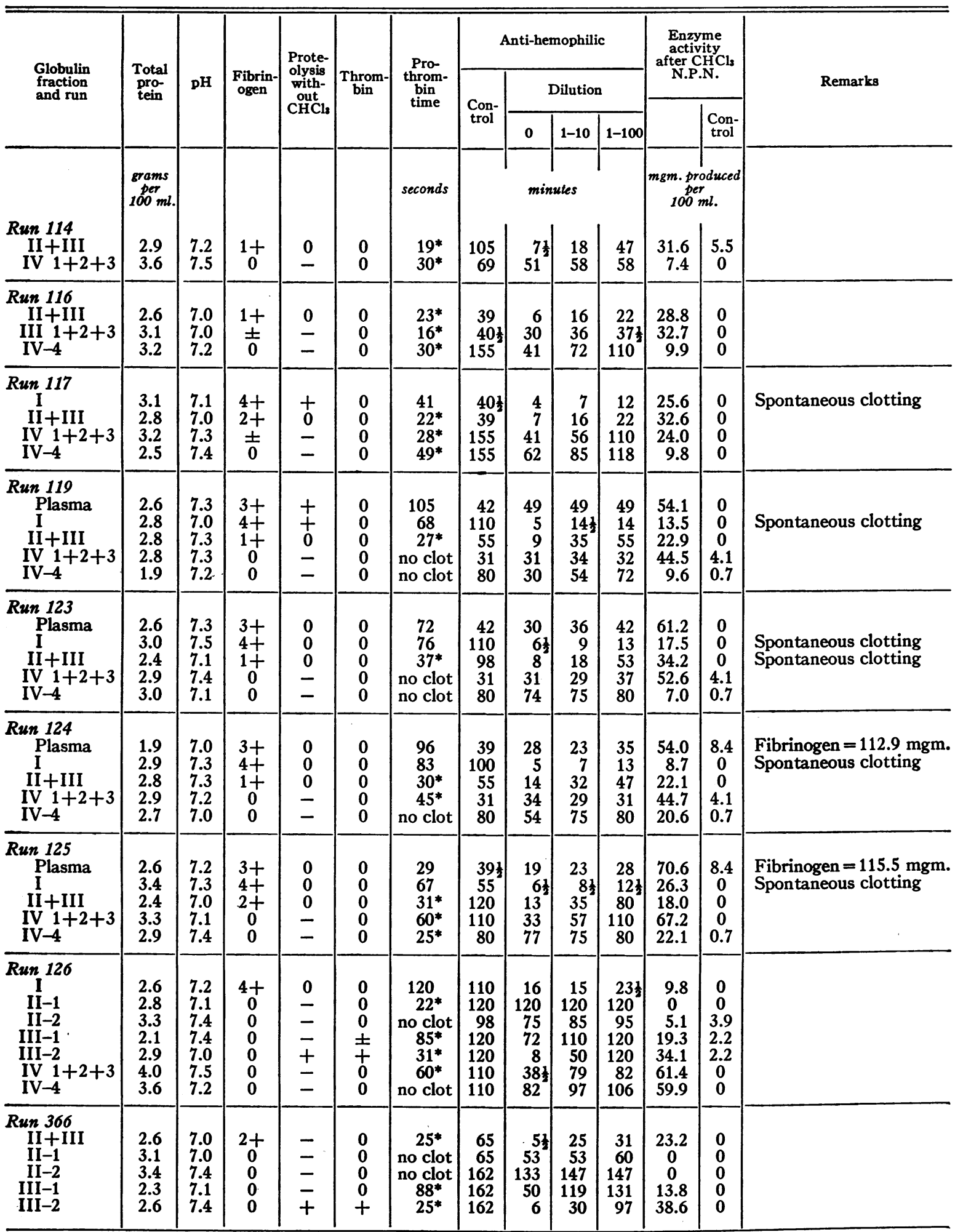

$*=0.1 \mathrm{ml}$. fibrinogen solution added in the usual Quick test. 
clotting potency equal to Fraction I. The antihemophilic properties of runs $117,119,123,124$, and 125 were in all probability enhanced by the presence of some proteolytic enzyme in the preparation which is known to have some coagulating effect per se. While Fraction I is a potent source of antihemophilic material, it should be borne in mind that from 60 to 80 per cent of this fraction is fibrinogen so that the possibility remains that further separation of the components of Fraction I may give rise to greater concentration of this activity.

An analysis of the combined Fraction II and III is shown in runs 126 and 366 . Here it is shown that the fraction most active in antihemophilic properties lies in Fraction III, sub-fraction 2. The results are somewhat obscured due to the presence of traces of preformed thrombin in the fraction. Actually the amount present was so small that over 1 hour was required to obtain a clot with pure fibrinogen solution. It is possible, therefore, that while the small amount of thrombin present, and also the small amount of protease, may have enhanced the antihemophilic activity, they did not account for the marked reduction in the clotting time observed. It is also noteworthy that while Fraction III-2 contains antihemophilic activity, it is devoid of fibrinogen.

Plasma proteolytic enzyme. It will be observed that a proteolytic enzyme after treatment with chloroform can be obtained from the parent plasma and from all of the main fractions studied. The parent plasma contains more of the enzyme than any of the sub-fractions. It is to be noted that the protein content of the plasma is in close proximity to the values obtained for the 4 per cent solutions of the fractions. Of the fractions themselves, the greatest concentration of the enzyme is obtained in Fraction IV which is devoid of fibrinogen and of antihemophilic activity. Hence, it would appear that certain fractions can be a good source for the preparation of the plasma proteolytic enzyme in the absence of antihemophilic activity. The amount of prothrombin present is also usually small in Fraction IV. In Fraction III the fibrinolytic enzyme is largely concentrated in Fraction III-2 which also is capable of lytic action on fibrinogen without the previous preparation with chloroform. Similar lytic action is oc- casionally found in Fraction I and probably accounts for the instability of solutions of this fraction (16). Spontaneous clotting and lysis of solutions of Fraction I have been frequently observed as indicated in the table.

Prothrombin and thrombin. The plasma prothrombin was found chiefly in Fraction II + III and occasionally in Fraction IV. Only minute traces remained in the parent plasma. Traces of preformed thrombin are occasionally found, chiefly in Fraction III-2.

Fibrinogen. As would be expected from previous reports (9), fibrinogen was largely found in Fraction I with occasional traces present in Fraction II + III. Fraction IV contained no fibrinogen.

\section{DISCUSSION}

Interest centers chiefly around the occurrence and distribution of antihemophilic and proteolytic activity in the various fractions and sub-fractions of the plasma globulins. The separation of a highly potent antihemophilic fraction capable of administration in small amounts to hemophilic patients is desirable. Previous investigations at this laboratory have shown that prothrombin and fibrinogen can be separated from the antihemophilic globulin (2). This separation in Fraction I has not yet been accomplished. However, Fraction III-2 contains marked antihemophilic activity but no fibrinogen, so that one may hope for a satisfactory separation in the near future.

The finding that proteolytic activity could be obtained by the treatment of Fraction IV by chloroform is of some academic interest. It clearly shows that fractions containing no antihemophilic activity may be a source of proteolytic enzyme. However, it should be borne in mind that the antihemophilic property of plasma is very labile so that in the preparation of Fraction IV it may have been destroyed. Furthermore, it has been shown (1) that there is a great possibility for adsorption of the antihemophilic property on fibrinogen and since this material has been removed before the preparation of Fraction IV, much of the antihemophilic activity might well be removed with it. The high potency of Fraction I which contains 60 to 70 per cent of the fibrinogen would partially confirm this possibility.

Antihemophilic activity quite often is adsorbed 
with prothrombin (1) which may well account for an increase in the activity of Fraction II + III which contains the bulk of the prothrombin. Fraction IV is devoid of both fibrinogen and prothrombin which may well account for the absence of antihemophilic activity in this fraction of the plasma globulin. Another purely speculative reason for the absence of antihemophilic properties in Fraction IV may be that inhibitor materials have been concentrated in this fraction. Such inhibitors are in fact known (16).

The low potency of antihemophilic activity in the parent plasma requires comment. Fresh human plasma is an excellent source of this material. It is known from in vitro studies that stored liquid plasma and plasma dried from the frozen state (15) contain minimal amounts of antihemophilic activity. Furthermore, stored whole blood and liquid plasma are not effective in vivo in reducing the coagulation time of the blood of hemophilic patients (17). Hence, either in the preparation of Fraction $I$ the plasma contained much more of the antihemophilic material than the specimens examined in the dried state or the concentration of the fibrinogen in this fraction served also to concentrate the minimal amounts of the antihemophilic activity remaining in the parent plasma.

The presence of a protease in Fraction I confirms to a large degree our opinion regarding the cause of the instability of fibrinogen solutions. It has been noted in this laboratory that in the presence of plasma protease fibrinogen solutions clot and the clot lyses within a short time (17).

The foregoing in vitro observations suggest that by further subfractionation a highly potent injectable material may be found which may have some value in the treatment of hemophilic patients. Preliminary observations of the effect of injection in hemophilia of a suitable fraction for the commencement of such chemical fractionation are given in the accompanying paper. Furthermore, the data suggest that from Fraction III-2 or Fraction IV a sub-fraction may be obtained which will be a highly potent source of the proteolytic enzyme $(7,5)$.

\section{CONCLUSIONS}

1. The antihemophilic property of normal human plasma appears to be associated with the pro- teins of Fraction I of Cohn. It is also found in high concentration in Fraction III, sub-fraction 2.

2. The plasma proteolytic enzyme $(7,5)$ may be prepared from Fractions I, II + III, and IV. In Fractions I and III-2 a proteolytic activity without treatment with chloroform can occasionally be demonstrated.

3. The proteolytic activity after treatment with chloroform can be obtained from Fraction IV which is devoid of antihemophilic activity, fibrinogen and prothrombin.

\section{BIBLIOGRAPHY}

1. Patek, A. J., Jr., and Taylor, F. H. L., Hemophilia. II. Some properties of a substance obtained from normal human plasma effective in accelerating the coagulation of hemophilic blood. J. Clin. Invest., 1937, 16, 113.

2. Lozner, E. L., Kark, R., and Taylor, F. H. L., The coagulation defect in hemophilia: the clot promoting activity in hemophilia of berkefelded normal human plasma free from fibrinogen and prothrombin. J. Clin. Invest., 1939, 18, 603.

3. Lozner, E. L., and Taylor, F. H. L., The coagulation defect in hemophilia : studies of the clot promoting activity associated with plasma euglobin in hemophilia. J. Clin. Invest., 1939, 18, 821.

4. Adams, M. A., and Taylor, F. H. L., The thrombic activity of a globulin fraction of the plasma proteins of beef, swine and human blood. Am. J. M. Sc., 1943, 205, 538.

5. Tagnon, H. J., Davidson, C. S., and Taylor, F. H. L., Studies of blood coagulation: a proteolytic enzyme prepared from calcium and platelet free normal human blood plasma. J. Clin. Invest., 1942, 21, 525.

6. Kaplan, M. H., Tagnon, H. J., Davidson, C. S., and Taylor, F. H. L., Studies on blood coagulation: the nature and properties of a proteolytic enzyme derived from plasma. J. Clin. Invest., 1942, 21, 533.

7. Tagnon, H. J., The significance of fibrinolysis in mechanism of coagulation of blood. J. Lab. and Clin. Med., 1942, 27, 1119.

8. Edsall, J. T., Ferry, R. M., and Armstrong, S. H., Jr., Chemical, clinical, and immunological studies on the products of human plasma fractionation. $\mathrm{XV}$. The proteins concerned in the blood coagulation mechanism. J. Clin. Invest., 1944, 23, 557.

9. Cohn, E. J., Oncley, J. L., Strong, L. E., Hughes, W. L., Jr., and Armstrong, S. H. Jr., Chemical, clinical, and immunological studies on the products of human plasma fractionation. I. The characterization of the protein fractions of human plasma. J. Clin. Invest., 1944, 23, 417.

10. Eagle, H., and Harris, T. N., Studies in blood co- 
agulation. V. The coagulation of blood by proteolytic enzymes (trypsin, papain). J. Gen. Physiol., 1937, 20, 543.

11. Milstone, H., Purification of thrombin. J. Gen. Physiol., 1942, 25, 679.

12. Souter, A. W., and Kark, R., Quick's prothrombin time simplified by the use of stable thromboplastin. Am. J. M. Sc., 1940, 200, 603.

13. Quick, A. J., Stanley-Brown, M., and Bancroft, F. W., Study of the coagulation defect in hemophilia and in jaundice. Am. J. M. Sc., 1935, 190, 501.
14. Howell, W. H., Hemophilia. Bull. New York Acad. Med., 1939, 15, 3.

15. Taylor, F. H. L., Lozner, E. L., Davidson, C. S., Tagnon, H. J., and Newhouser, L. R., Preservation of normal human plasma in the liquid state. II. Comparative in vitro studies on the physiologic activity of labile constituents of liquid and frozen plasma. J. Clin. Invest. 1944, 23, 351.

16. Tagnon, H. J., Davidson, C. S., and Taylor, F. H. L., Unpublished observations.

17. Davidson, C. S., Unpublished observations. 